\title{
Сибирский вектор трудовой миграции: тенденции последних лет
}

З.И. КАЛУГИНА, доктор СОциологических наук, Институт экономики и организации промышленного производства СО РАН, Новосибирск. E-mail: zima@ieie.nsc.ru

В статье анализируются масштабы, направления и последствия трудовой миграции в регионах Сибири и Российской Федерации, рассматривается ее динамика в ситуации экономического спада, отмечаются положительные и отрицательные последствия международной трудовой миграции, а также угрозы и риски нелегальной трудовой миграции. Отмечены возрастающие масштабы миграционной активности населения, изменение состава мигрантов, география и цели их перемещений. Представлена динамика численности иностранных граждан, имеющих разрешение на работу в РФ и Сибирском федеральном округе. Ключевые слова: трудовая миграция, иностранная рабочая сила, рынок труда, вектор оттока и притока населения

Глобализация экономической жизни, интернационализация общественных процессов, характерные для текущего столетия, привели в движение огромные пласты людских потоков, направляющихся в поисках лучшей доли из одних стран и континентов на другие. Гонимые войнами, межнациональными конфликтами, разрухой и деградацией национальных экономик миграционные волны накрыли Европу и Азию.

По данным Международной организации по миграции, к середине 1990-х годов число мигрантов по сравнению с 1960 г. возросло с 3,2 до 35 млн человек, в 2008 г. - 93 млн (3\% мировых трудовых ресурсов), а к 2010 г. уже насчитывалось 215,8 млн официальных мигрантов и около 100 млн нелегальных [1].

По данным ООН, в 2015 г. 244 млн человек проживали за пределами стран, где они родились. По сравнению с 2000 г. число международных мигрантов выросло в 2015 г. на 41\%, а удельный вес в мировом населении достиг 3,3\%. Однако существуют значительные различия между крупными регионами мира. В Европе, Северной Америке и Океании доля международных мигрантов в общей численности населения составляет не менее $10 \%$, тогда как в Африке, Азии, Латинской Америке и странах Карибского бассейна, не достигает $2 \%$ [2]. 
Россия, по данным ООН, в 2015 г. занимала третье место в мире по числу международных мигрантов (эмигрантов) по стране происхождения (10576766 человек, или 6,87\% от населения страны), и одновременно второе место по числу иммигрантов (12080000, или 8,43\% от населения страны), т.е. в 2015 г. в Россию прибыло на 1,5 млн больше человек, чем выбыло [3].

Значительную долю в миграционных потоках занимает трудовая миграция, наращивание которой является для многих стран одним из способов решения демографических и экономических задач [4].

Международная трудовая миграция регулируется Конвенцией о защите прав всех трудящихся, принятой Генеральной Ассамблеей ООН в резолюции № 45/158 от 18 апреля 1990 г. Документ определяет термин «трудящийся-мигрант» как лицо, которое будет заниматься, занимается или занималось оплачиваемой деятельностью в государстве, гражданином которой он не является [5].

Виды трудовой миграции:

- безвозвратная, когда мигрант покидает свою страну навсегда и выезжает на ПМЖ в принимающее государство;

- длительное пребывание за границей в пределах 1-6 лет;

- сезонное или кратковременное (не более одного года) пребывание в стране для работы в отраслях, имеющих сезонный характер (туристические услуги, рыбная ловля, сельское хозяйство и др.);

- маятниковая миграция, характеризующаяся ежедневным (еженедельным) пересечением границы для работы в соседней стране;

• нелегальный, несанкционированный въезд в другую страну на работу или законное пребывание с нелегальным трудоустройством;

- перемещение высококвалифицированных кадров: ученых, специалистов редких профессий, представителей мира искусства, спортсменов.

Возрастающие масштабы миграционной активности населения, изменение состава мигрантов, географии и целей их перемещений ставят перед странами, теряющими и принимающими людские потоки, непростые задачи. Это касается замещения освободившихся рабочих мест и трудоустройства вновь приехавших, решение проблем интеграции и адаптации мигрантов в новом сообществе, совмещения разных культур и моделей поведения различных национальных и конфессиональных групп. Опыт, в том числе и негативный, европейских государств показывает всю сложность, противоречивость и неоднозначность этих задач.

\section{Динамика трудовой миграции в РФ и Сибирском федеральном округе}

Статистика показывает, что российский рынок труда остается привлекательным для выходцев из стран ближнего и дальнего зарубежья. В период с 2010 г. по 2015 г. ежегодный миграционный прирост населения РФ составил 158,1-319,8-294,9-295,8-280,3245,4 тыс. чел. [6. С. 32]. В 2016 г. число прибывших трудовых мигрантов, по оценкам экспертов, не превысило 600 тыс. человек, выбытия находились на уровне, превышающем 300 тыс. В результате миграционный прирост за год составил около 280 тыс. человек [7].

Важнейшие факторы трудовой миграции - наличие свободных рабочих мест и благосостояние населения, одним из индикаторов которого являются среднедушевые доходы. С этой точки зрения Сибирь, несмотря на ее необъятные просторы и богатейшие природные ресурсы, не слишком привлекательный регион для трудовых мигрантов.

Согласно статистическим данным на 01.01.2016 г. среднедушевые денежные доходы сибиряков отставали от среднероссийских показателей примерно на 29\%. В совокупности - 1,7 млн человек $(8,8 \%)$ имели доход ниже прожиточного минимума, более 4 млн (23\%) располагали доходами ниже минимального потребительского бюджета (бюджет выживания). Доля бедных слоев населения среди сибиряков в 2015 г. Значительно превышала среднероссийские показатели и варьировала от 13,9\% в Омской области до $38,2 \%$ - в Республике Тыва. Прослойка из обеспеченных слоев населения с доходами свыше 45000 руб. в Сибири значительно ниже, чем в Российской Федерации и варьирует от 4,3\% в Республике Алтай до 14,6\% - в Красноярском крае, в то время как по РФ доля обеспеченного населения составляла в 2015 г. 18,6\% [8. С. 260-261].

Неизбежным следствием отставания социально-экономического развития сибирских регионов является миграционный отток населения, наблюдаемый практически во всех субъектах Сибирского федерального округа (СФО). Исключение составляют Новосибирская и Томская области (рисунок). По итогам 5 ЭКО. - 2017. - № 12 
2013-2015 гг. за счет миграции население СФО сократилось соответственно на 15178,8146 и 10586 чел. [9. С. 99-100]

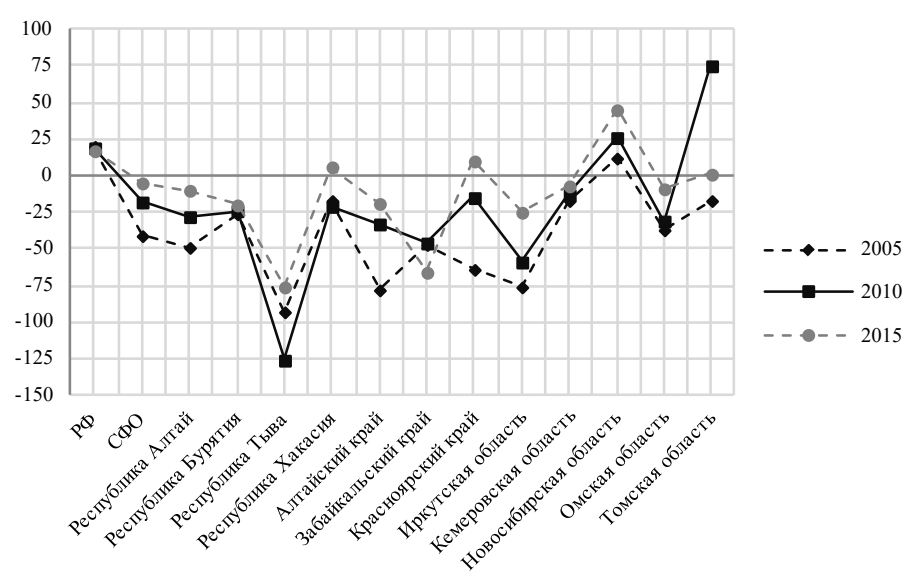

Источник: Регионы России. Социально-экономические показатели. 2016 Стат. сб./ Росстат.- М., 2016.- С. 80-81.

Коэффициенты миграционного прироста на 10000 чел. населения в РФ и СФО, 2005-2015 гг.

Очевидно, что сибирские просторы привлекают мигрантов не столько перспективой получения высоких доходов, сколько возможностью найти постоянную работу.

Пополняют Сибирь в основном жители других регионов РФ. Выходцы из других государств составляют не более 10\%. Для них наиболее привлекательными остаются Дальний Восток, Москва и Московская область, Санкт-Петербург и Ленинградская область, где выше заработная плата и есть свободные рабочие места.

Статистика показывает, что характер и масштабы внешней миграции на территории Сибири существенно изменились после 2008 г., когда резко упал спрос на иностранную рабочую силу в связи с разразившимся финансово-экономическим кризисом. Эти тенденции сохраняются и в настоящее время, так как ограничительные международные санкции также отрицательно сказались на развитии отечественной экономики.

Если в начале 2000-х годов (2001-2005 гг.) среднегодовой прирост ВВП в РФ составил 6,2\%, в 2006-2010 гг. он был на уровне $3,6 \%$, то в 2011-2015 гг. - составил только 1,2\%
[9. С. 32]. Соответственно спрос на отечественную и иностранную рабочую силу в этот период заметно снизился во всех регионах страны.

Тем не менее по сравнению с 2000 г. в 2015 г. численность мигрантов, прибывших в РФ из-за рубежа, увеличилась в 1,7 раза, в том числе из стран СНГ - в 1,6 раза, из стран ЕС - в 1,8 раза, а из других стран - в 1,6 раза [9. С. 94].

В 2015 г. в Россию прибыло из зарубежных стран 598,6 тыс. человек, выбыло за рубеж 353 тыс. человек, миграционный прирост составил 245 тыс. человек. При этом в 2014-2015 гг. доля «внутренних» мигрантов среди всех прибывших составила 87\%, среди выбывших - 92\% [10].

Положительное сальдо миграции наблюдалось в Центральном, Южном и Северо-Западном округах. Коэффициенты миграционного прироста здесь составили соответственно 57, 34 и 16 промилле. Заметный отток населения наблюдался в СевероКавказском (-26) и Дальневосточном федеральных округах (-39) промилле. В Сибирском федеральном округе миграционные потери населения были незначительными (-5) промилле [9. С. 80-81]

На протяжении многих лет основными поставщиками иностранных мигрантов в Россию являются бывшие союзные республики: Узбекистан, Таджикистан, Украина и Киргизия. Выходцы из этих стран составляют не менее $3 / 4$ от общего числа трудовых мигрантов. Это вызвано высокой рождаемостью населения, обусловленной религиозными представлениями и национальными традициями, и неразвитостью экономик этих стран.

\section{Уровень образования и профессиональная подготовка иностранной и отечественной рабочей силы}

В составе мигрантов из стран СНГ превалируют когорты молодых возрастов от 18 до 30, а также 30-39 лет. В совокупности они составляют почти $3 / 4$ общей численности. Квалификация большинства из них низкая, они используются в основном на строительных, ремонтно-строительных и других работах, не требующих профессиональных навыков.

Мигранты, приезжающие в Россию из дальнего зарубежья, представляют собой группу более зрелых возрастов. Группы 
в возрасте 30-39 и 40-49 лет составляют более $60 \%$ в их общей численности.

Специфика сибирского вектора трудовой миграции заключается в том, что в СФО по сравнению с Российской Федерацией значительно выше доля мигрантов, имеющих рабочие профессии, занятых на строительно-монтажных и ремонтно-строительных работах, но заметно ниже доля специалистов среднего уровня квалификации физических и инженерных сфер деятельности. Для экономики Сибири характерна также более низкая доля квалифицированных рабочих всех отраслей экономики и работников сферы индивидуальных услуг и охраны населения (таблица).

\section{Распределение иностранных граждан, имевших действующее разрешение на работу в СФО, по профессиональным группам в 2016 г. (на конец года)}

\begin{tabular}{|l|c|c|}
\hline \multicolumn{1}{|c|}{ Показатель } & \multicolumn{2}{|c|}{ СФ0 } \\
\cline { 2 - 4 } & чел. & $\%$ \\
\hline Всего иностранных граждан & 72626 & 100,0 \\
\hline $\begin{array}{l}\text { Руководители учреждений, организаций и предприятий и их структурных } \\
\text { подразделений (служб) }\end{array}$ & 801 & 3,2 \\
\hline Специалисты в области естественных и инженерных наук & 238 & 0,9 \\
\hline $\begin{array}{l}\text { Специалисты среднего уровня квалификации физических и инженерных направле- } \\
\text { ний деятельности }\end{array}$ & 234 & 0,9 \\
\hline $\begin{array}{l}\text { Средний персонал в области финансово-экономической, административной } \\
\text { и социальной деятельности }\end{array}$ & 734 & 2,9 \\
\hline Работники сферы индивидуальных услуг и защиты граждан и собственности & 478 & 1,9 \\
\hline Продавцы, демонстраторы товаров, натурщики и демонстраторы одежды & 123 & 0,5 \\
\hline $\begin{array}{l}\text { Квалифицированные работники товарного сельскохозяйственного производства, } \\
\text { лесного, охотничьего хозяйств, рыбоводства и рыболовства, имеющие рыночную } \\
\text { ориентацию }\end{array}$ & 1275 & 5,0 \\
\hline $\begin{array}{l}\text { Рабочие, занятые на горных, горнокапитальных и на строительно-монтажных } \\
\text { и ремонтно-строительных работах }\end{array}$ & 14732 & 58,2 \\
\hline Рабочие металлообрабатывающей и машиностроительной промышленности & 1453 & 5,7 \\
\hline $\begin{array}{l}\text { Другие профессии квалифицированных рабочих крупных и мелких промышленных } \\
\text { предприятий }\end{array}$ & 1663 & 6,6 \\
\hline Операторы, аппаратчики и машинисты промышленных установок & 1188 & 4,7 \\
\hline $\begin{array}{l}\text { Операторы, аппаратчики и машинисты и слесари-сборщики стационарного } \\
\text { оборудования }\end{array}$ & 709 & 2,8 \\
\hline Водители и машинисты подвижного оборудования & 342 & 1,4 \\
\hline Квалифицированные рабочие, общие для всех отраслей экономики & 176 & 0,7 \\
\hline Иные профессионально-квалификационные группы & 1170 & 4,6 \\
\hline
\end{tabular}

Источник: [11].

\section{Угрозы и риски трудовой миграции}

Наряду с положительными последствиями международная миграция в условиях демографического спада коренного населения страны может превратиться в форму колонизации и замещения населения, привести не только к росту криминальной составляющей бытовых правонарушений, но и к росту преступности экстремистского характера. По свидетельствам директора ФМС РФ, г-на Ромодановского, на территории России находится около 20 млн легальных и нелегальных мигрантов, около 70\% из которых «исповедуют» ислам.

Мигранты повышают напряженность на региональных рынках труда. Официально численность безработных в России не превышает 5,6\% от экономически активного населения, а время поиска работы занимает в среднем от 6 до 8,5 месяцев. При этом разрыв в уровне безработицы между различными регионами России доходит до 18 раз. Минимальная доля безработных отмечена в Петербурге $(1,6 \%)$ и Москве $(1,7)$, максимальная в Ингушетии $(28,8)$ и Тыве $(17,5 \%)$.

В Сибирском федеральном округе уровень занятости населения 2015 г. составлял $62,5 \%$, а уровень безработицы $-8 \%$. При этом среднее время поиска работы составляло 7,7 месяцев, а доля застойной безработицы (время поиска работы более 12 месяцев) была на уровне 31,4\% [8. С. 198-199].

Но особенно сильные угрозы и риски несет нелегальная трудовая миграция.

Точных данных о ее масштабах не существует, экспертные оценки общей численности различаются - от 1,5 до 15 млн человек, в том числе приехавших из стран дальнего зарубежья - от нескольких сот тысяч до 2 млн. По другим оценкам, в Российской Федерации находятся с нарушениями паспортно-визового и иммиграционного режимов, трудового законодательства не менее 5 млн иностранных граждан и лиц без гражданства. Это лица, прибывшие из 60 стран с неблагоприятной внутриполитической, социально-экономической, экологической, санитарно-эпидемиологической и сложной демографической обстановкой [12].

Негативные последствия нелегальной миграции очевидны. Это, прежде всего, повышение уровня криминализации общества, ухудшение санитарно-эпидемиологической обстановки в районах 
приема нелегальных мигрантов, угроза терроризма и экстремистских религиозных настроений в обществе.

Угрозой национальной безопасности страны, связанной с нелегальной миграцией, является состояние здоровья мигрантов. В России проживает 10,2 млн мигрантов, но только 10\% из них ежегодно проходят медицинское освидетельствование. Этого недостаточно для борьбы с опасными заболеваниями, в том числе с ВИЧ-инфекцией и туберкулёзом. Одной из основных проблем, связанных с бесконтрольной миграцией, являются либеральные нормы по пересечению гражданами республик СНГ границы с Российской Федерацией и их последующего учета [13].

Совет по межнациональным отношениям при Президенте РФ готовит пакет предложений по противодействию нелегальной миграции. Будет ли содействовать этому процессу ликвидация специализированной миграционной службы (ФМС) как отдельного ведомства и передача их функций Министерству внутренних дел (указ Президента № 156 от 5.04.2016), покажет время.

Одним из направлений борьбы с нелегальной миграцией и ее последствиями является миграционная амнистия (легализация лиц, нелегально находящихся на территории страны). По мнению главы Федерации мигрантов России В. Коженова, гражданская амнистия - это эффективный способ сокращения нелегального сектора миграции. Как свидетельствует международный опыт, миграционные амнистии выводят из тени от 18 до 47\% находящихся в стране нелегалов. По его мнению, легализация теневого сектора миграции может увеличить ежегодные поступления в бюджет России от патентных сборов около 20-60 млрд руб. Кроме того, это поможет сократить опасность распространения болезней и эпидемий среди мигрантов, так как они должны будут пройти медицинское освидетельствование [12]. Однако в России о миграционной амнистии речь пока не идет.

Подводя итоги вышесказанному, можно отметить, что занятость иностранной рабочей силы на национальных рынках труда - это распространенная международная практика, которая сопровождается как положительными, так и негативными последствиями. Дилемма, отраженная в авторской статье «Технический прогресс или трудовая миграция» [14], в современном российском обществе не снята с повестки дня.

\section{Литература}

1. URL: http://topmigrant.ru/migraciya/obshhaya-informaciya/trudovayamigraciya.html

2. URL: http://reliefweb.int/report/world/trends-international-migrantstock-2015-revision

3. International Migrant Stock: The 2015 Revision //https://ru.wikipedia org/wiki/\%D0\%A1\%D0\%BF\%D0\%B8\%D1\%81\%D0\%BE\%D0\%BA \%D1\% $81 \% D 1 \% 82 \% D 1 \% 80 \% D 0 \% B 0 \% D 0 \% B D \_\% 0 \% B F \% D 0 \% B E \_\% 1 \% 87 \%$ D0\%B8\%D1\%81\%D0\%BB\%D0\%B5\%D0\%BD\%D0\%BD\%D0\%BE\%D1\%8 1\%D1\%82\%D0\%B8 \%D0\%BC\%D0\%B8\%D0\%B3\%D1\%80\%D0\%B0\%D 0\%BD\%D1\%82\%D0\%BE\%D0\%B2\#.D0.A7.DO.B8.D1.81.DO.BB.DO.B5. DO.BD.DO.BD.DO.BE.D1.81.D1.82.D1.8C_.DO.BC.DO.B5.DO.B6.DO.B4. D1.83.D0.BD.D0.B0.D1.80.D0.BE.D0.B4.D0.BD.D1.8B.D1.85 .DO.BC. D0.B8.D0.B3.D1.80.D0.BO.DO.BD.D1.82.DO.BE.DO.B2 2015 .DO.BF D0.BE_.D1.81.D1.82.D1.80.D0.BO.DO.BD.DO.B5_.DO.BF.D1.80.DO.BE. DO.B8.D1.81.D1.85.DO.BE.DO.B6.DO.B4.DO.B5.DO.BD.DO.B8.D1.8F

4. Аганбегян А.Г. Социально-экономическое развитие России анализ и прогноз URL: http://cyberleninka.ru/article/n/sotsialnoekonomicheskoe-razvitie-rossii-analiz-i-prognoz

5. URL: http://migration.academic.ru/106/\%D0\%A2\%D1\%80\%D1\%83\% D0\%B4\%D0\%BE\%D0\%B2\%D0\%B0\%D1\%8F_\%D0\%BC\%D0\%B8\%D0\% B3\%D1\%80\%D0\%B0\%D1\%86\%D0\%B8\%D1\%8F

6. Россия в цифрах. 2016: Крат.стат. сб./Росстат.- М., 2016.- 543 с.

7. URL: http://ria.ru/society/20161206/148296297/html

8. Регионы России. Социально-экономические показатели. 2016: Стат. сб. / Росстат.- М., 2016.- 1326 с.

9. Российский статистический ежегодник. 2015: Стат. сб.- М., 2015.$543 \mathrm{c}$.

10. Численность и миграция населения Российской Федерации в 2015 году. URL: http://www.gks.ru/bgd/regl/b16_107/Main.htm 11. URL: http://docs.cntd.ru/document/420331346

12. URL: http://www.fmr-online.ru/2017/01/09/president-federaciimigrantov-rossii-dal-interviu-gazete-izvestia/

13. Алексей Живов. Мигранты - новое население РФ, или угроза национальной безопасности? // URL: https://zlyerusskie.com/migrants/ 14. Калугина 3.И. Технический прогресс или трудовая миграция? // ЭКО.- 2013.- № 1.- С. 99-116. 